\title{
Relationship between fasting plasma glucose, atherosclerosis risk factors and carotid intima media thickness in non-diabetic individuals
}

\author{
T. Temelkova-Kurktschiev, C. Koehler, F. Schaper, E. Henkel, A. Hahnefeld, K. Fuecker, G. Siegert, M. Hanefeld
}

\begin{abstract}
Summary We analysed the relationship between fasting plasma glucose, carotid intima media thickness and some atherosclerosis risk factors in 307 non-diabetic individuals. Male $(n=120)$ and female subjects $(n=187)$ with a familial history of Type II diabetes mellitus and/or obesity and hyperlipoproteinaemia were examined in the age group $40-70$ years. Plasma triglycerides, total and high-density-lipoprotein cholesterol, plasminogen activator inhibitor were measured by conventional methods. Specific insulin, proinsulin and C-peptide were measured by specific enzyme immunoassay. Intima media thickness increased in quintiles for fasting plasma glucose in men, but not in women. There was a rise of triglycerides, body mass index, waist to hip ratio, plasminogen activator inhibitor, true insulin, proinsulin, C-peptide and a decrease of high-density-lipoprotein cholester$\mathrm{ol}$ in quintiles for fasting plasma glucose. Fasting plasma glucose was found to be significantly positively correlated to intima media thickness, body mass index, waist to hip ratio, haemoglobin $\mathrm{A}_{1 \mathrm{c}}$, insulin, $\mathrm{C}$ peptide, triglycerides, plasminogen activator inhibi-
\end{abstract}

tor and significantly negatively correlated to high density lipoprotein cholesterol. However, the correlation of fasting plasma glucose to intima media thickness was no longer significant after adjustment for age and sex. After adjustment for age and sex intima media thickness was significantly correlated to body mass index, total cholesterol, triglycerides, albuminuria and inversely correlated to high-density-lipoprotein cholesterol. In multivariate analysis age, male sex, high-density-lipoprotein cholesterol and total cholesterol were significant determinants of intima media thickness. Our data suggest that a weak association exists between fasting plasma glucose and intima media thickness, which may be mediated by a clustering of risk factors in the upper range of non-diabetic fasting plasma glucose level with a central role for dyslipidaemia. [Diabetologia (1998) 41: 706-712]

Keywords Intima media thickness, atherosclerosis, fasting plasma glucose, lipoproteins, insulin, proinsulin, endothelial dysfunction, blood pressure.
Received: 21 August 1997 and in final revised form: 3 February 1998

Corresponding author: Dr. T. Temelkova-Kurktschiev, Institute and Outpatient Clinic of Metabolic Research, University Clinic "C.G. Carus" of the Technical University Dresden, Dresden, Germany

Abbreviations: FPG, Fasting plasma glucose; CVD, cardiovascular disease; IMT, intima media thickness; CCA, common carotid artery; IGT, impaired glucose tolerance; $\mathrm{HbA}_{1 \mathrm{c}}$, haemoglobin $\mathrm{A}_{1 \mathrm{c}}$; PAI, plasminogen activator inhibitor; BMI, body mass index; WHR, waist to hip ratio; HDL, high density lipoprotein.
Hyperglycaemia has been convincingly shown to be associated with increased occurrence of atherosclerosis [1-4]. Epidemiological studies found that patients with Type II (non-insulin-dependent) diabetes mellitus have a two- to four-fold increased relative risk of cardiovascular disease (CVD) in comparison to nondiabetic subjects [3]. Poorly controlled Type II diabetic patients have a higher risk than patients with good glycaemic control [1, 4]. Furthermore, there is evidence that non-diabetic plasma glucose levels are also continuously associated with CVD [5-7], though this relationship has not been confirmed for only moderate degrees of hyperglycaemia [8-10]. So far, 
Table 1. Baseline characteristics by sex

\begin{tabular}{|c|c|c|c|}
\hline & Male & Female & $p$ value \\
\hline$n$ & 120 & 187 & \\
\hline Age (years) & $54.2 \pm 0.8(52.7 \ldots 55.8)$ & $54.8 \pm 0.6(53.6 \ldots 55.9)$ & NS \\
\hline Body mass index $\left(\mathrm{kg} / \mathrm{m}^{2}\right)$ & $26.8 \pm 0.3(26.1 \ldots 27.4)$ & $26.8 \pm 0.3(26.2 \ldots 27.5)$ & NS \\
\hline Waist to hip ratio & $0.96 \pm 0.006(0.95 \ldots 0.97)$ & $0.83 \pm 0.005(0.82 \ldots 0.84)$ & $<0.001$ \\
\hline Systolic blood & $134 \pm 1.7(130.9 \ldots 137.8)$ & $134 \pm 1.3(131.3 \ldots 136.4)$ & NS \\
\hline pressure (mm Hg) & & & NS \\
\hline $\begin{array}{l}\text { Fasting plasma } \\
\text { glucose }(\mathrm{mmol} / \mathrm{l})\end{array}$ & $6.02 \pm 0.06(5.91 \ldots 6.13)$ & $5.71 \pm 0.04(5.63 \ldots 5.79)$ & $<0.001$ \\
\hline $\mathrm{HbA}_{1 \mathrm{C}}(\%)$ & $5.6 \pm 0.04(5.50 \ldots 5.67)$ & $5.5 \pm 0.04(5.43 \ldots 5.57)$ & NS \\
\hline Fasting specific insulin (pmol/l) & $83.5 \pm 5.9(71.8 \ldots 95.2)$ & $70.7 \pm 3.0(64.7 \ldots 76.7)$ & 0.03 \\
\hline Fasting proinsulin $(\mathrm{pmol} / \mathrm{l})$ & $2.24 \pm 0.18(1.88 \ldots 2.59)$ & $1.83 \pm 0.13(1.58 \ldots 2.07)$ & NS \\
\hline C-peptide $(\mathrm{pmol} / \mathrm{l})$ & $1232 \pm 56.7(1122 \ldots 1349)$ & $1122 \pm 29.9(1062 \ldots 1181)$ & 0.06 \\
\hline Total cholesterol (mmol/l) & $5.8 \pm 0.11(5.61 \ldots 6.03)$ & $5.8 \pm 0.07(5.68 \ldots 5.98)$ & NS \\
\hline Triglycerides (mmol/l) & $1.98 \pm 0.18(1.62 \ldots 2.33)$ & $1.28 \pm 0.04(1.20 \ldots 1.36)$ & $<0.001$ \\
\hline HDL-cholesterol (mmol/l) & $1.2 \pm 0.03(1.19 \ldots 1.32)$ & $1.7 \pm 0.03(1.61 \ldots 1.73)$ & $<0.001$ \\
\hline Intima media thickness maximal (mm) & $1.03 \pm 0.02(0.99 \ldots 1.08)$ & $0.89 \pm 0.01(0.87 \ldots 0.92)$ & $<0.001$ \\
\hline Intima media thickness mean (mm) & $0.9 \pm 0.02(0.86 \ldots 0.93)$ & $0.79 \pm 0.01(0.77 \ldots 0.82)$ & $<0.001$ \\
\hline PAI active $(\mathrm{ng} / \mathrm{ml})$ & $47.1 \pm 4.21(38.63 \ldots 55.49)$ & $33.1 \pm 2.46(28.27 \ldots 37.98)$ & 0.003 \\
\hline
\end{tabular}

Data are mean \pm SEM (95\% confidence interval)

it is an open question whether plasma glucose is a continuous cardiovascular risk factor in its entire spectrum, including the euglycaemic range, as suggested by Gerstein and Yusuf [7, 11], or rather there is a curvilinear relationship with a threshold effect at the near-diabetic level.

Most of the epidemiological data are based on the mortality or incidence rate of CVD and little is known about the relationship of plasma glucose concentration and the vessel status examined by ultrasound. The measurement of the intima media thickness (IMT) of the common carotid artery (CCA), as originally described by Pignoli et al. [12] is a highly reproducible and suitable non-invasive method to monitor early stages of atherosclerosis [13-15]. IMT of the CCA was shown to be related to cardiovascular risk factors and occurrence of CVD [16, 17] and is considered an early marker of coronary atherosclerosis. Recently several studies reported an increased carotid IMT in diabetic subjects $[18,19]$. Furthermore, there is some evidence supporting the hypothesis that in the absence of diabetes blood glucose control, measured by haemoglobin $\mathrm{A}_{1 \mathrm{c}}$, may be a risk factor for carotid intima media thickening [20]. So far, there is no published data on the relationship of fasting plasma glucose (FPG) and IMT in the European population.

The aim of this study was to examine how FPG is related to carotid IMT in middle-aged non-diabetic individuals. To shed some light on the nature of the association between plasma glucose and atherosclerosis, which is far from clear up to now, we analysed the relationship between FPG and insulin/proinsulin, as well as to some established risk factors such as plasma lipoproteins, blood pressure and endothelial function parameters.

\section{Subjects and methods}

Subjects. All study participants were involved in an ongoing prospective survey on Risk factors in IGT for Atherosclerosis and Diabetes (the RIAD Study), which started in August 1996. For this study middle-aged subjects from the city of Dresden and its surroundings were invited to participate, who had risk for the development of diabetes, such as familial history of type 2 diabetes, obesity and/or hyper/dyslipoproteinaemia. As recruitment sources we used newspaper advertisements and articles, invitations to relatives of dyslipidaemic and/or diabetic patients as well as to patients with dyslipoproteinaemia. All candidates were admitted if they met the following criteria: age between 40 and 70 years; no history of diabetes; no renal insufficiency; no severe diseases with a shortage of life expectancy; no medication (thiazide diuretics, beta blockers, corticosteroids) known to affect glucose tolerance. The RIAD participants underwent a standard examination according to a special protocol including: short physical examination by a physician for blood pressure, waist to hip ratio and body mass index; standard OGTT with 75 g glucose; ECG; questionnaire about lifestyle, familial history, concomitant diseases and medication; examination of accepted risk factors for atherosclerosis; ultrasound examination of the carotid and femoral arteries. For technical reasons the IMT measurement of the CCA was started in November 1996 and was conducted in all RIAD participants thereafter $(n=469)$. According to the RIAD study design all subjects will be checked by a second examination in 3 years.

In this study we analysed the data of participants with a complete examination programme (including IMT measurement). The newly detected diabetic patients $(n=84)$ according to the still valid criteria of the World Health Organisation [21] were excluded from analysis. Another exclusion criterion for the present study was lipid lowering treatment, so that 78 participants receiving lipid lowering drugs were excluded from analysis. The baseline characteristics of the analysed subjects ( $n=307 ; 120$ male and 187 female) are shown in Table 1 .

Ultrasound measurement. Ultrasonography of the distal CCA was conducted bilaterally with an Acuson 128XP Computed Sonography System using a $10 \mathrm{MHz}$ linear array transducer. 
Patients were examined in a supine position. We used a longitudinal 2-dimensional ultrasound image of the CCA, which is displayed as two bright echorich lines separated by a hypoechogenic space. A careful search was performed for the IMT of the far wall of the distal CCA. When an optimal image was obtained it was frozen in an end-diastolic phase, to minimize variability during the cardiac cycle. IMT was measured twice bilaterally at $0.5 \mathrm{~cm}$ and $1 \mathrm{~cm}$ proximal from the dilatation of the CCA. The mean of these values presented the $\mathrm{IMT}_{\text {mean }}$ of each subject. In addition the maximal thickness (IMT $\max$ ) was measured. All scans were conducted by only two physicians under the supervision of one expert. All final IMT data are based on computer stored images that were evaluated by one researcher. The examination was performed on the day of blood collection for laboratory analysis, so that both patients and physicians were unaware of the corresponding laboratory values. The reproducibility of the IMT measurement was determined by a second scan in 24 patients within 3 months from the baseline examination. The mean difference in IMT between these two examinations was $0.01 \mathrm{~mm}$ and the correlation between them -0.916 for the right CCA IMT, 0.957 for the left CCA IMT, 0.969 for IMT max $_{\text {and }} 0.984$ for IMT $_{\text {mean }}$ demonstrating good reproducibility.

Laboratory examination. Patients were examined after an overnight fast of at least $10 \mathrm{~h}$. Citrate and EDTA plasma and serum were separated by centrifugation (4000 rev/min for $8 \mathrm{~min}$ at $4^{\circ} \mathrm{C}$ ). Aliquots of plasma and serum were immediately frozen with liquid nitrogen and were stored at $-80^{\circ} \mathrm{C}$ until analysis. Plasma glucose and $\mathrm{HbA}_{1 \mathrm{c}}$ were determined using fresh material. Serum was used for analysis of proinsulin, insulin and C-peptide. Plasminogen activator inhibitor (PAI) was estimated in Stabylite citrate plasma. $\mathrm{HbA}_{1 \mathrm{c}}$ was examined by high performance liquid chromatography (HPLC) on a Diamat analyser (BioRad Laboratories, München, Germany). Plasma glucose was measured by the hexokinase method (interassay $\mathrm{CV}=1.5 \%$ ). After precipitation with dextran sulfate HDL cholesterol was examined in the upper layer on a Ciba Corning Express Plus analyser (Ciba Corning Diagnostics, Fernwald, Germany). Triglycerides and total cholesterol were measured by enzyme colorimetric assay on a Ciba Corning Express Plus analyser, using commercially available test kits (Boehringer, Mannheim, Germany). Proinsulin was measured by enzyme immunoassay (DGR Instruments, Marburg, Germany) The monoclonal antibody used in this assay recognizes a proinsulin specific epitope. It showed cross-reactivity with $32-33$ split proinsulin of less than $1.5 \%$ and none with human insulin and human C-peptide (interassay coefficient of variation ranged from 16 to $10 \%$ using controls prepared at 1.8, 7.3 and $12.5 \mathrm{pmol} / \mathrm{l}$ proinsulin). The lower limit of detection of the proinsulin assay was $0.5 \mathrm{pmol} / 1$. Specific insulin and C-peptide were also measured by enzyme immunoassay (Medgenix Diagnostics, Fleurus, Belgium). Specific insulin (interassay $\mathrm{CV}=7.6 \%$ ) showed no cross-reactivity to human proinsulin. The cross-reactivity of C-peptide assay to human proinsulin was $12.5 \%$ (interassay C-peptide $\mathrm{CV}=<11 \%$ ). PAI was determined using commercially available enzyme immunoassays (Immuno AG, Heidelberg, Germany). Urine was collected as fresh morning urine samples. Albuminuria was measured by nephelometry (Nephelometer BNII, Behring, Germany).

Statistical analysis. Data evaluation was conducted using the SPSS/PC + programme. Quintiles for FPG were built and IMT as well as metabolic parameters corresponding to these five groups were compared by one-way ANOVA and $t$-test. The distribution of values was assessed by the Levene test for homogeneity of variances and the Mann-Whitney U test was performed if necessary. The level of significance was determined as $p$ less than 0.05 . Data are presented as mean and $95 \%$ confidence interval for mean (CI). The correlation between FPG and examined parameters as well as between IMT and risk factors were assessed using Pearson correlation coefficients. In addition, partial correlation after adjustment for age and gender was evaluated. Multivariate analysis for IMT determinants was conducted by linear regression.

\section{Results}

The examined individuals, 120 males and 187 females, were of middle age and with mild obesity (Table 1). Female subjects showed significantly lower WHR, triglycerides and significantly higher HDL cholesterol levels. In addition, they had significantly lower FPG, insulin, PAI as well as lower IMT. The sex difference in IMT persisted after adjustment for FPG.

In men carotid IMT, both mean and maximal, increased in quintiles for FPG reaching statistical significance in the fifth quintile, whereas in women there was no relevant difference for IMT between the FPG quintiles (Fig. 1). In parallel IMT increased in quintiles of $\mathrm{HbA}_{1 \mathrm{c}}$.

In men we observed a rise of triglycerides, BMI and WHR and a parallel decrease of HDL cholesterol in quintiles for FPG (Table 2). The level of total cholesterol was similar in FPG quintiles. PAI increased in quintiles for FPG. Albuminuria did not differ between the five quintiles. Specific insulin, proinsulin, and C-peptide increased in FPG quintiles (Fig. 2). In women similar changes for the examined parameters were observed in FPG quintiles, the difference being significant mostly between the first and the fifth quintile (Table 2).

FPG was found to be significantly positively correlated to $\mathrm{IMT}_{\text {max }}, \mathrm{IMT}_{\text {mean }}$, BMI, WHR, $\mathrm{HbA}_{1 \mathrm{c}}$, insulin, C-peptide, triglycerides, PAI and significantly negatively correlated to HDL cholesterol (Table 3). However, the correlation of FPG to IMT was no longer significant after adjustment for age and sex. IMT was significantly positively correlated to WHR, blood pressure, $\mathrm{HbA}_{1 \mathrm{c}}$, total cholesterol, triglycerides, albuminuria and FPG and significantly negatively correlated to HDL cholesterol. After adjustment for age and sex IMT was significantly correlated to BMI, total cholesterol, triglycerides, albuminuria and inversely correlated to HDL cholesterol. Variables chosen for further multivariate modeling were significant at the $p=0.10$ level in univariate analysis. In multivariate analysis age, male sex, total and HDL cholesterol were found to be significant determinants of IMT (Table 4). When analysed separately for gender - age, BMI and HDL cholesterol were independent risk factors for IMT in men and age and total cholesterol - in women. 

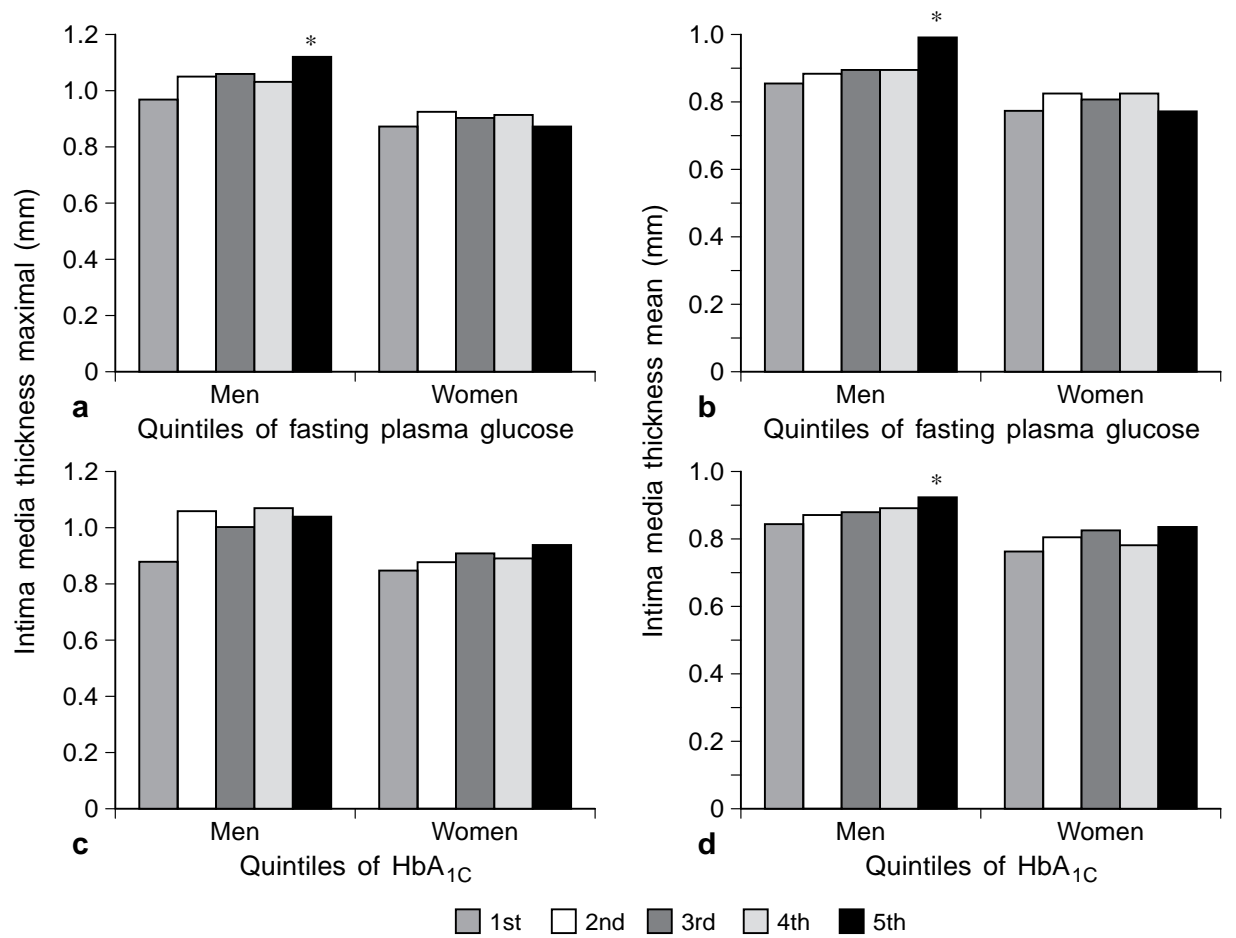

Fig. 1. Intima media thickness of the carotids by quintiles of fasting plasma glucose (FPG) and $\mathrm{HbA}_{1 \mathrm{c}}$ for men and women. In men: $1 \mathrm{Q} 4.4 \geq \mathrm{HbA}_{1 \mathrm{c}}<5.2 ; 2 \mathrm{Q} 5.2 \geq \mathrm{HbA}_{1 \mathrm{c}}<5.4 ; 3 \mathrm{Q}$ $5.4 \geq \mathrm{HbA}_{1 \mathrm{c}}<5.7 ; \quad 4 \mathrm{Q} \quad 5.7 \geq \mathrm{HbA}_{1 \mathrm{c}}<5.9 ; \quad 5 \mathrm{Q} \quad 5.9 \geq$ $\mathrm{HbA}_{1 \mathrm{c}}<7.3$. In women: 1Q $3.2 \leq \mathrm{HbA}_{1 \mathrm{c}}<5.16$; 2Q $5.16 \leq$ $\mathrm{HbA}_{1 \mathrm{c}}<5.4 ; 3 \mathrm{Q} 5.4 \leq \mathrm{HbA}_{1 \mathrm{c}}<5.6 ; 4 \mathrm{Q} 5.6 \leq \mathrm{HbA}_{1 \mathrm{c}}<5.84$; 5Q $5.84 \leq \mathrm{HbA}_{1 \mathrm{c}}<6.9$

$* \mathrm{p}<0.05$ v.s. $1 \mathrm{Q}$

\section{Discussion}

Though there is a general agreement that hyperglycaemia is associated with atherosclerosis, recent findings indicate that glycaemic level as a cardiovascular risk factor in the normal population and in diabetic subjects constitute two separate questions [22]. Several prospective studies have demonstrated that hyperglycaemia in non-diabetic subjects is predictive for subsequent development of CVD $[5,7,11]$. In a metaanalysis of more than one million of person-years of follow-up in mainly non-diabetic populations a con-

Table 2. Risk factors in quintiles of fasting plasma glucose for 120 men (M) and 187 woman (W) (mean (95\% confidence interval))

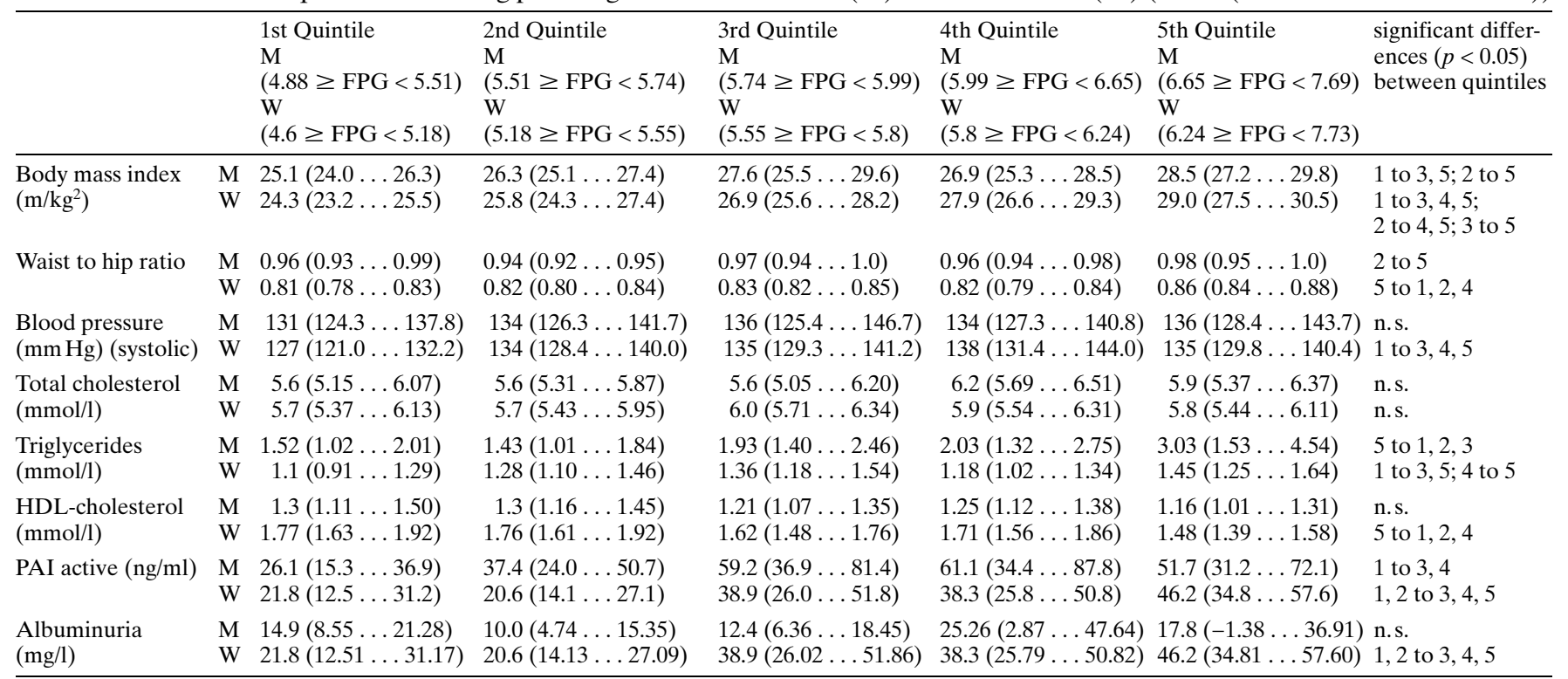


Table 3. Correlation of IMT and plasma glucose to possible atherosclerosis risk factors

\begin{tabular}{|c|c|c|c|c|}
\hline \multirow[t]{3}{*}{ Parameters } & \multicolumn{4}{|c|}{ Dependent variable } \\
\hline & \multicolumn{2}{|l|}{ Plasma glucose } & \multicolumn{2}{|l|}{ IMT mean } \\
\hline & Unadjusted $(p)$ & $\begin{array}{l}\text { After sex and age } \\
\text { adjustment }(p)\end{array}$ & Unadjusted $(p)$ & $\begin{array}{l}\text { After sex and age } \\
\text { adjustment }(p)\end{array}$ \\
\hline IMT mean & $0.15(0.007)$ & $0.04(\mathrm{NS})$ & - & - \\
\hline Age & $0.08(\mathrm{NS})$ & - & $0.38(<0.001)$ & - \\
\hline Sex & $-0.25(<0.001)$ & - & $-0.29(<0.001)$ & - \\
\hline Body mass index & $0.3(<0.001)$ & $0.3(0.001)$ & $0.07(\mathrm{NS})$ & $0.12(0.04)$ \\
\hline Waist to hip ratio & $0.3(<0.001)$ & $0.14(0.02)$ & $0.26(<0.001)$ & $0.04(\mathrm{NS})$ \\
\hline Blood pressure systolic & $0.1(\mathrm{NS})$ & $0.09(\mathrm{NS})$ & $0.17(0.004)$ & $0.08(\mathrm{NS})$ \\
\hline Total cholesterol & $0.02(\mathrm{NS})$ & $0.02(\mathrm{NS})$ & $0.14(0.01)$ & $0.11(0.07)$ \\
\hline Triglycerides & $0.26(<0.001)$ & $0.22(<0.001)$ & $0.15(0.008)$ & $0.16(0.006)$ \\
\hline HDL-Cholesterol & $-0.27(<0.001)$ & $-0.18(0.002)$ & $-0.22(<0.001)$ & $-0.16(0.006)$ \\
\hline $\mathrm{HbA}_{1 \mathrm{C}}$ & $0.35(<0.001)$ & $0.33(<0.001)$ & $0.15(0.01)$ & $0.03(\mathrm{NS})$ \\
\hline Fasting specific insulin & $0.32(<0.001)$ & $0.31(<0.001)$ & $0.05(\mathrm{NS})$ & 0.06 (NS) \\
\hline Fasting proinsulin & $0.07(\mathrm{NS})$ & $0.07(\mathrm{NS})$ & $0.07(\mathrm{NS})$ & 0.08 (NS) \\
\hline Fasting C-peptide & $0.3(<0.001)$ & $0.28(<0.001)$ & $0.11(0.05)$ & 0.09 (NS) \\
\hline PAI active & $0.3(<0.001)$ & $0.25(<0.001)$ & $0.12(0.05)$ & $0.08(\mathrm{NS})$ \\
\hline Albuminuria & $0.07(\mathrm{NS})$ & $0.04(\mathrm{NS})$ & $0.17(0.01)$ & $0.15(0.02)$ \\
\hline
\end{tabular}

Table 4. Multivariate analysis of risk factors of IMT max and IMT mean for the total group and by gender

\begin{tabular}{|c|c|c|c|c|c|c|}
\hline \multirow[t]{2}{*}{ Parameters } & \multicolumn{3}{|c|}{ IMT max } & \multicolumn{3}{|c|}{ IMT mean } \\
\hline & all & male & female & all & male & female \\
\hline Age & $<0.001$ & 0.002 & $<0.001$ & $<0.001$ & 0.001 & $<0.001$ \\
\hline Sex & 0.003 & - & - & 0.003 & - & - \\
\hline $\begin{array}{l}\text { Body mass } \\
\text { index }\end{array}$ & NS & 0.04 & NS & NS & 0.05 & NS \\
\hline $\begin{array}{l}\text { Waist to hip } \\
\text { ratio }\end{array}$ & NS & NS & NS & NS & NS & NS \\
\hline $\begin{array}{l}\text { Systolic blood } \\
\text { pressure }\end{array}$ & NS & NS & NS & NS & NS & NS \\
\hline $\begin{array}{l}\text { Total } \\
\text { cholesterol }\end{array}$ & 0.009 & NS & 0.004 & 0.02 & NS & 0.02 \\
\hline Triglycerides & NS & NS & NS & NS & NS & NS \\
\hline $\begin{array}{l}\text { HDL- } \\
\text { cholesterol }\end{array}$ & 0.04 & 0.002 & NS & NS & 0.004 & NS \\
\hline $\mathrm{HbA}_{1 \mathrm{C}}$ & NS & NS & NS & NS & NS & NS \\
\hline C-peptide & NS & NS & NS & NS & NS & NS \\
\hline PAI active & NS & NS & NS & NS & NS & NS \\
\hline Albuminuria & NS & NS & NS & 0.053 & NS & NS \\
\hline
\end{tabular}

tinuous increase in risk of CVD with glucose levels $>4.2 \mathrm{mmol} / \mathrm{l}$ could be demonstrated [11]. Hyperglycaemia, however, was not a significant risk factor in three other large prospective studies [8-10]. Recently a review assessed the association of glycaemia and cardiovascular risk stating that while hyperglycaemia in diabetes seems an established risk factor for atherosclersosis, evidence for the role of plasma glucose in non-diabetic subjects is weak and inconsistent [23]. So far, studies on this issue were based on CVD events and evaluation of the relationship between FPG and carotid IMT, a good marker of early atherosclerosis, had not been conducted. The impact of hyperglycaemia on IMT was already described in Japanese subjects with impaired glucose tolerance [19] and in Type II diabetic patients [18]. Our study provides data on the relationship between FPG and carotid IMT in a middle-aged non-diabetic European population. The results indicate that in non-diabetic men carotid IMT increases in parallel with glucose levels (Fig. 1). This finding is consistent with a recent study showing that carotid IMT increases with higher $\mathrm{HbA}_{1 \mathrm{c}}$ levels in non-diabetic individuals [20]. However, it remains an open question as to whether or not FPG is causally related to IMT. It seems likely that elevated FPG levels may act through associated risk factors. Thus, there was a rise of triglycerides, BMI, WHR and PAI together with a decrease of HDL cholesterol in FPG quintiles, this difference reaching statistical significance mostly in the fifth quintile (Table 2). Since there is evidence that hypertriglyceridaemia [24], android obesity [24, 25], disturbed fibrinolysis [26] and low HDL cholesterol [27] could be considered as risk factors for atherosclerosis, the clustering of these could explain the intima media thickening in the upper FPG quintiles in men. The significant difference of IMT by FPG quintiles in men disappeared after adjustment for age (Table 2). Similarly, the univariate correlation of FPG and IMT was no longer significant after adjustment for age and sex (Table 3). In the multivariate analysis FPG was not an independent risk factor for increased IMT and established risk factors such as age, male sex, total and HDL cholesterol were found to be independent IMT determinants (Table 4). This is in agreement with other findings for determinants of carotid IMT [28]. Our data on the relationship between FPG and early atherosclerosis in non-diabetic subjects, measured by ultrasound, is compatible with the literature, based on CVD events. If the new Ameri- 


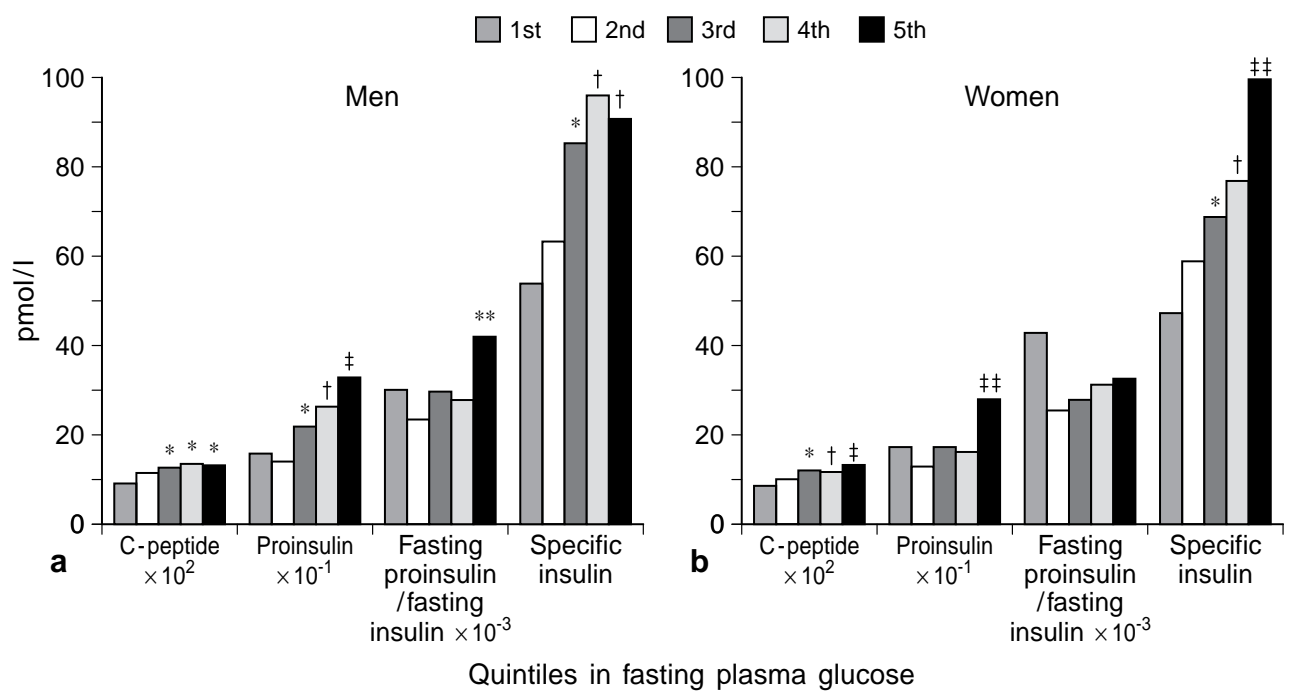

Fig. 2. Average levels (data mean) of specific insulin, proinsulin, C-peptide and the proinsulin to insulin ratio in quintiles of fasting plasma glucose in men (a) and women (b) in non-diabetic subjects

$* \mathrm{p}<0.05$ v.s. Q1; ** $\mathrm{p}<0.05$ v.s. Q2; $\uparrow \mathrm{p}<0.05$ v. s. Q1, Q2

$\neq \mathrm{p}<0.05$ v.s. Q1, Q2, Q3; 㧊 $\mathrm{p}<0.05$ v.s. Q1, Q2, Q3, Q4

can Diabetes Association criteria for the diagnosis of Type II diabetes [29] are taken into consideration, some subjects from the fifth quintile would be excluded from analysis, which could weaken the association.

In non-diabetic women no significant changes were found in IMT in FPG quintiles (Fig. 1). Interestingly, female subjects had a significantly thinner intima-media than male subjects together with a lower FPG (Table 1). After adjustment for FPG the IMT difference remained significant. In the Rancho Bernardo study an increase of FPG from 5 to $7 \mathrm{mmol} / \mathrm{l}$ was associated with a doubling of CHD mortality in men and a tripling in women [5]. In the present study with both sexes in the same age and BMI range, males exhibit the classical risk profile of the metabolic syndrome: higher levels of insulin, triglycerides, PAI, WHR and lower levels of HDL cholesterol, together with a more pronounced IMT than females.

Total cholesterol and albuminuria, as expected, were not related to glucose levels, but were significantly correlated to IMT even after adjustment for age and sex (Table 2 and 3). These results are compatible with other studies on the impact of albuminuria and in particular of total cholesterol on carotid IMT $[28,30]$. Blood pressure was significantly higher in the fifth FPG quintile for women (Table 2) and was significantly correlated to IMT (Table 3 ). Recently blood pressure was reported as determinant for IMT in non-diabetic subjects [31]. However, in our study the partial correlation to IMT was no longer significant after age and sex adjustment, which could be due to the fact that a high percentage of the hypertensive subjects were under medical treatment.

Hyperinsulinaemia and insulin resistance have been suggested to play a role in accelerated atherogenesis $[32,33]$. Interestingly, insulin levels in our study were found to increase in euglycaemia and mild dysglycaemia, preceding diabetes. An increase was observed in both specific insulin and proinsulin in quintiles of FPG. The increment of proinsulin to insulin ratio, indicative of impaired insulin secretion, was significantly elevated in the fifth FPG quintile in men. In addition, triglycerides may reflect insulin resistance in our subjects in parallel with hyperglycaemia. As shown in Table 3 there is a close correlation of FPG with insulin fractions, triglycerides and PAI. These components of the metabolic syndrome were found in our study to increase at a level of FPG of $5.55-5.8 \mathrm{mmol} / \mathrm{l}$ in women and $5.44-5.99 \mathrm{mmol} / 1$ in men.

In conclusion, our data in non-diabetic individuals clearly demonstrate an increase in established atherosclerosis risk factors in the 4th and 5th quintile of FPG below the old and new cut-off level for diabetes. In the euglycaemic range we observed a continuous rise in specific insulin and proinsulin. IMT was significantly increased in the top quintile of FPG only in men. In multivariate analysis age, male sex, total and HDL cholesterol were independent risk factors. Our data suggest a weak association to exist between FPG and IMT, which may be mediated by a clustering of risk factors in the upper range of non-diabetic FPG level with a central role of dyslipidaemia.

Acknowledgements. We very much appreciate the excellent technical assistance by B. Blaurock, U. Buro, I. Schiebeck, B. Zeiler, I. Heidrich, G. Haumann. 


\section{References}

1. Laakso M, Kuusisto J (1996) Epidemiological evidence for the association of hyperglycaemia and atherosclerotic vascular disease in non-insulin-dependent diabetes mellitus. Ann Med 28: 415-418

2. Klein R (1995) Hyperglycaemia and microvascular and macrovascular disease in diabetes. Diabetes Care 18: 258-268

3. Kannel WB, McGee DL (1979) Diabetes and cardiovascular disease. The Framingham study. J Am Med Assoc 241: 2035-2038

4. Andersson DKG, Svardsudd K (1995) Long-term glycaemic control relates to mortality in type II diabetes. Diabetes Care 18: 1534-1543

5. Scheidt-Nave C, Barrett-Connor E, Wingard DL, Cohn BA, Edelstein SL (1991) Sex differences in fasting glycemia as a risk factor for ischemic heart disease death. Am J Epidemiol 133: 565-576

6. Pais P, Pogue J, Gerstein H et al. (1996) Risk factors for acute myocardial infarction in Indians: a case-control study. Lancet 348: 358-363

7. Gerstein HG, Yusuf S (1996) Dysglycaemia and risk of cardiovascular disease. Lancet 347: 949-950

8. Pyörälä K, Savolainen E, Lehtovirta E, Punsar S, Siltanen P (1979) Glucose tolerance and coronary heart disease: Helsinki Policemen Study. J Chron Dis 32: 729-745

9. Stamler R, Stamler J, Lindberg HA et al. (1979) Asymptomatic hyperglycaemia and coronary heart disease in middle-aged men in two employed populations in Chicago. $\mathrm{J}$ Chron Dis 32: 805-815

10. Ohlson LO, Svardsud K, Welin L, Eriksson H, Wilhelmsen L, Tibblin G, Larsson B (1986) Fasting blood glucose and risk of coronary heart disease, stroke, and all-cause mortality: a 17-year follow-up study of men born in 1913. Diabet Med 3: 33-37

11. Gerstein HG (1997) Glucose: a continuous risk factor for cardiovascular disease. Diabet Med 14:S25-S31

12. Pignoli P, Tremoli E, Poli A, Oreste P, Paoletti R (1986) Intimal plus medial thickness of the arterial wall: A direct measurement with ultrasound imaging. Circulation 74 : 1399-1406

13. Belcaro G, Geroulakos G, Laurora G et al. (1993) Inter/intra-observer variability of carotid and femoral bifurcation intima-media thickness measurements. Panminerva Med 35(2):75-79

14. Bots ML, Mulder PG, Hofman A, Es GA van, Grobbee DE (1994) Reproducibility of carotid vessel wall thickness measurements. The Rotterdam Study. J Clin Epidemiol 47(8):921-930

15. Persson J, Stavenow L, Wikstrand J, Israelsson B, Formgren J, Berglund G (1992) Noninvasive quantification of atherosclerotic lesions. Reproducibility of ultrasonographic measurement of arterial wall thickness and plaque size. Arteriosclerosis Thrombosis 12: 261-266

16. Heiss G, Sharett AR, Barnes R, Chambless LE, Szklo M, Alzola C, for the ARIC Investigators (1991) Carotid atherosclerosis measured by B-mode ultrasound in populations: associations with cardiovascular risk factors in the ARIC study. Am J Epidemiol 134: 250-256
17. Salonen JT, Salonen R (1991) Ultrasonographically assessed carotid morphology and the risk of coronary heart disease. Arterioscler Thromb 11: 1245-1249

18. Niskanen L, Rauramaa R, Miettinen H, Haffner SM, Mercuri M, Uusitupa M (1996) Carotid artery intima-media thickness in elderly patients with NIDDM and in non-diabetic subjects. Stroke 27: 1986-1992

19. Yamasaki Y, Kawamori R, Matsushima H et al. (1995) Asymptomatic hyperglycaemia is associated with increased intimal plus medial thickness of the carotid artery. Diabetologia 38: 585-591

20. Vitelli LL, Shahar E, Heiss G, McGovern PG, Brancati FL, Eckfeldt JH, Folsom AR for the Atherosclerosis Risk in Communities (ARIC) Study Investigators (1997) Glycosylated haemoglobin level and carotid intimal-medial thickening in non-diabetic individuals. Diabetes Care 20: $1454-1458$

21. World Health Organization Study Group on Diabetes Mellitus (1985) Diabetes mellitus: report of a WHO Study Group. World Health Organization (Tech. Rep. Ser., no. 727), Geneva, pp 94-98

22. Stern MP (1997) Glycemia and cardiovascular risk. Diabetes Care 20: 1501-1502

23. Barrett-Connor E (1997) Does hyperglycaemia really cause coronary heart disease? Diabetes Care 20: 1620-1623

24. Assmann G, Schulte H (1992) The importance of triglycerides: results from the Prospective Cardiovascular Munster (PROCAM) Study. Eur J Epidemiol 8: 99-103

25. Kissebah AH (1996) Intra-abdominal fat: is it a major factor in developing diabetes and coronary artery disease? Diabetes Res Clin Pract 30: 25-30

26. Salomaa V, Stinson V, Kark JD, Folsom AR, Davis CE, Wu KK (1995) Association of fibrinolytic parameters with early atherosclerosis. The ARIC Study. Atherosclerosis Risk in Communities Study. Circulation 91: 284-290

27. Buring JE, O'Connor GT, Goldhaber SZ et al. (1992) Decreased HDL2 and HDL3 cholesterol, apo A-I and apo AII, and increased risk of myocardial infarction. Circulation 85: 22-29

28. Joensuu T, Salonen R, Winblad I, Korpela H, Salonen JT (1994) Determinants of femoral and carotid artery atherosclerosis. J Intern Med 236: 79-84

29. The Expert Committee on the Diagnosis and Classification of Diabetes mellitus (1997) Report of the Expert Committee on the Diagnosis and Classification of Diabetes mellitus. Diabetes Care 20: 1183-1197

30. Bigazzi R, Bianchi S, Nenci R, Baldari D, Baldari G, Campese VM (1995) Increased thickness of the carotid artery in patients with essential hypertension and microalbuminuria. J Hum Hypertens 9: 827-833

31. Pan WH, Bai CH, Chen JR, Chiu HC (1997) Association between carotid atherosclerosis and high factor VIII activity, dyslipidaemia, and hypertension. Stroke 28: 88-94

32. Haller H, Drab M, Luft FC (1996) The role of hyperglycaemia and hyperinsulinemia in the pathogenesis of diabetic angiopathy. Clin Nephrol 46: 246-255

33. Baron AD (1996) Insulin and the vasculature - old actors, new roles. J Investig Med 44: 406-412 